\title{
LOS MUDÉJARES, SEGÚN LA RIḤLA DE IBN AṢ-ṢABBĀḤ (M. DESPUÉS 895/1490)
}

Francisco Franco Sánchez

\section{INTRODUCCIÓN ${ }^{1}$}

Los mudéjares buscaron conservar su idiosincrasia islámica. Entre sus realizaciones, sabemos que quienes podían no dejaban de hacer la peregrinación a los Santos Lugares del Islam, o haŷŷ, a pesar de los peligros de todo tipo -interiores y externos- que conllevaba su realización. Diversas fuentes nos informan de ello, pero ninguna de ellas es tan vívida y fiable como las relaciones que ellos mismos dejaron escritas ${ }^{2}$.

En diversa medida se han conservado los relatos de estas experiencias referidos por viajeros y peregrinos mudéjares, y su estudio ha sido ya realizado por especialistas como M. Epalza, Cl. Sarnelli, M. Razzouq, Y̌. Šayja... por no citar sino algunos relevantes, desde diversos puntos de vista.

Un personaje con una personalidad de gran atractivo y una importante obra, a quien no se le ha concedio la relevancia merecida es 'Abd Alläh Ibn Ass-Ṣabbāh Al-Aṣbahị Al-Andalusĩ. Debemos su conocimiento al Prof. Ŷuma'a Šayja, quien ha presentado al autor en algunas monografías ${ }^{3}$; él dio a conocer el manuscrito $n^{\circ}$. 2295 de la Dār Al-Kutūb Al-Wataniyya de Túnez, que contiene la única obra conocida de Ibn Aș-Ṣabbāḥ, titulada Minšăấ ${ }^{u}$ al-

1. Deseo dejar constacia expresa de gratitud a la profesora Doña $\mathbf{M}^{a}$. Jesús RUBIERA, por orientarme sobre algunos aspectos del texto, y a los profs. Juan Sergio Nadal Cañellas y Hani Muhammad El-Eryan, por su ayuda para la correcta interpretación de ciertos pasajes.

2. Vid. al respecto L. P. HARVEY: «The moriscos and the Haŷy», Bulletin of the British Society for the Middle Eastern Studies, Londres, ${ }^{\circ}$. 14, 1988, pp. 11-24.

3. Djomaa CHeikHA: "Aspects religieux du récit de voyage de 'Abd Allah Ibn Al-Sabbah", Actas del III Simposio Internacional de Estudios Moriscos. Las prácticas religiosas de los moriscos andaluces (1492-1609), Zaghouan (Túnez), ed. CEROMDI, 1989, p. 55; id., "Quelques aspects religieux du récit de voyage de 'Abd Allah Ibn Al-Sabbah", Actes du IVe. Congrés International d'Etudes Morisques. Métiers, vie religieuse et problématiques d'histoire Morisque, Zaghouan, ed. CEROMDI, 1990, p. 356. 
ajbā $r^{i}$ wa-tadkirat ${ }^{u}$ al-ajyā $r^{i}$. Tomando como base este manuscrito el profesor Sayja ha estudiado la personal visión de la religión musulmana del autor y cómo presenta y piensa acerca de la sociedad mudéjar post-conquista de la Península Ibérica ${ }^{4}$. A la espera de la anunciada edición del texto íntegro de la relación de viaje de Ibn Aṣ-Ṣabbāh, Ŷ. Šayja ya ha adelantado diversos fragmentos, entre los que hay que notar aquellos en que se habla o describe el Reino de Granada ${ }^{5}$. En los estudios reseñados nos hemos basado. Presentamos, por tanto, una aproximación a un importante aspecto de la obra, que esperamos ampliar y profundizar cuando dispongamos de la prometida edición crítica del texto árabe.

\section{IBN AṣṢ̦ABBĀH, UN PEREGRINO ALMERIENSE}

Nuestro personaje, 'Abd Allāh Ibn Aṣ-Ṣabbāḥ Al-Aṣbahị no aparece reseñado en ninguno de los repertorios biográficos conocidos. El motivo parece ser que no pertenecía a ninguna de las categorías de sabios ulemas o al-

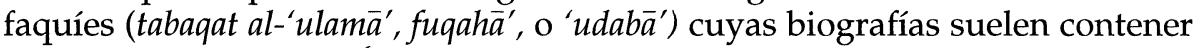
este tipo de repertorios ${ }^{6}$.

Un manuscrito de la Biblioteca Nacional de Túnez nos ha legado una obra cuya autoría se indica que fue de Ibn Aș-Ṣabbāh ${ }^{7}$. Se trata de una relación de viaje, esencialmente autobiográfica, en la que hallamos multitud de perfiles de análisis sobre la sociedad andalusí y mudéjar almeriense, además de informaciones diversas sobre las localidades y países por los que pasó.

Son los fragmentos conservados de esta rihla hiȳazziyya los que nos proporcionan el cañamazo básico para ensartar unos trazos biográficos fundamentales. Ibn Aș-Ṣabbāh pertenecía a la tribu de los Qaḥtāni (es) del sur, y de ella a la cábila de los Ṣabbāhì(es) del Yemen, abolengo que justifica el que no desprecie ni una oportunidad de vanagloriarse por ello, ensalzando el heroísmo de esta cábila, tanto en los tiempos preislámicos, como en la época islámica. Llega a asegurar, incluso, que esta cábila participó en la primera conquista de Al-Andalus ${ }^{8}$.

Lo primero que sabemos de él es que había habitado en la ciudad de Almería, habiendo establecido allí su residencia hasta después de ser toma-

4. Ŷuma'a ŠAYJA: «Ba'ḍ̣ al-mazāhir ad-dîniyya fî̀ rihlat 'Abd Allāh Ibn Aṣ-Ṣabbāḥ al-Andalusì», Dirāsāt Andalusiyya, Túnez, nº. 12, 1994 Juin/1415 Muharram, pp. 36-44.

5. Ŷuma'a Š SYYJA: «Mamlaka Banì l-Ahmar min jilāl "Minš̄āb al-ajbār wa-tadkirat al-ajyār" li-'Abd Allāh Ibn AṣSabbāh Al-Așbahì», Śharq Al-Andalus. Estudios Árabes. Homenaje a María Jesús Rubiera Mata, Alicante, $\mathrm{n}^{\circ}$. 10-11, 1993-1994, pp. 291-305.

6. Ŷ. ŠAYJA: «Ba'ḍal-mazāhir...», p. 36.

7. Dār Al-Kutūb Al-Wataniyya de Túnez, ms. n. 2295. Ver nota 3.

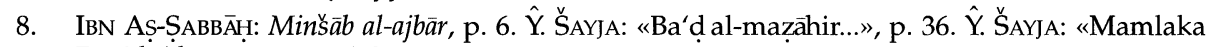
Banî l-Ạhmar ...», pp. 1-2. 
da por Fernando de Aragón en el año 895/1490. Sabemos también que fue un hậfiż, diciéndonos él mismo que memorizó el Alcorán durante una estancia en La Meca que duró un año completo; por ello, llegado el caso, emplea con profusión el Alcorán y los hadices en su obra. Durante su camino de peregrinación, declara que aprovechaba su estancia en las ciudades islámicas más importantes para aprender con los ulemas de su época.

Según el prof. Y. Šayja, a partir de su rihla se deduce que poseía mediana cultura religiosa y grandes conocimientos de historia, lo cual le sitúa por encima de la media cultural de los ulemas. Respecto a la lengua de la obra, en ocasiones su peculiar estilo induce a error, por lo enrevesado y por las expresiones dialectales que emplea, por lo cual no puede calificársele de buen escritor. En su descargo, no hay que olvidar la obra fue dictada oralmente ${ }^{9}$. Esta rihla, por ello, nos proporciona información valiosa sobre el nivel cultural habitual entre los musulmanes de la época de la conquista y entre los mudéjares ${ }^{10}$.

Ibn Aș-Sabbāh no podría haber hecho la peregrinación si no hubiera dispuesto dei dinero suficiente, que declara haber obtenido de modo legítimo (mâl halāl), como gusta de repetir, ya que lo había heredado de sus antepasados en Al-Andalus. Afirma además que sin juventud y salud no hubiera podido superar las dificultades y los peligros del viaje, los cuales detalla minuciosamente en su rihla hị̂̄aziyya ${ }^{11}$.

\section{LA RELACIÓN DE VIAJE DE IBN AṢ-ṢABBĀḤ}

\section{Características de la obra. CRONOlogía}

El manuscrito consigna como título Minšsābu al-ajbār ${ }^{i}$ wa-tadkirat ${ }^{u}$ alajyā ${ }^{i}$, acorde con la tradición cultural árabe de poner un encabezamiento poético a la obra compuesto de dos elementos. En cuanto a su significado, Minšă $b^{u}$ al-ajbā $r^{i}$ derivaría de našaba, "sujetar una cosa a otra", en forma mif'al, significando "donde se sujeta, ata, una cosa otra". El autor quería utilizar su rihla como un objeto en que "situar" sus noticias (biográficas, se entiende). Con tadkirat ${ }^{u}$ al-ajyāri, "últimos, postreros recuerdos", alude a su vivencia personal, rememorada en sus últimos días.

Ibn As-Sabbāh dictó su relación de viaje tras convertirse en mudéjares los habitantes de Almería, es decir después de su conquista en 895/1490 por

9. Esta oralidad, apuntes tomados de viva voz, explicaría el estilo. Quizás no fuera culpa suya el no haber encontrado, como Ibn Battūta, a un sultán como el soberano meriní Abū 'Inān (que ordenó escribir su relación de viaje y lo financió) y a un literato de la talla de un Ibn Yuzayy (que vertió el relato en prosa rimada).

10. Ŷ. ŠAYJA: «Ba'ḍal-mazāhir ...», p. 36.

11. Ibídem, p. 36. 
los castellanos del rey Fernando. Dice dictarla de memoria entre los 60 y los 70 años, cuando ya tenía debilitada la vista ${ }^{12}$. Como no se apunta fecha alguna para la realización del viaje, el Prof. Ŷ. Šayja se remite a los nombres de los sultanes turcos que menciona, como Murad II (que gobierna entre 824855/1421-1451), y a los ulemas citados, como Badr Ad-Dín Al-Balqíní AlMișrī (m. 890/1485). Se apunta finalmente la data de la década de 1450 y el principio de la de los años 1460, realizando la peregrinación cuando tenía entre 20 y 30 años $^{13}$.

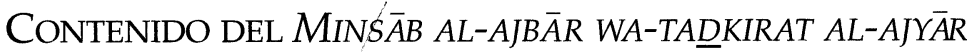

Este manuscrito cuenta el viaje que realizó 'Abd Allãh Ibn Aṣ-Ṣabbāḥ Al-Aṣbahì a La Meca y a los santos lugares del Islam. El itinerario del viaje es el siguiente: el autor sale de Almería hacia Granada, capital por entonces de los nazaríes (Banū l-Ahmar), se traslada a Ceuta, viajando a Marrākuš, Fez, Tlemcén y Orán, después Argel y Túnez, Trípoli (de Libia), Alejandría, llegando a El Cairo. Se encaminó luego a La Meca y Medina, y después a Jerusalén. De ella parte hacia el Bilād Ašs-Sam (o "Gran Siria": Siria, Jordania, Palestina, Líbano), continuando por Turquía, Persia e 'Irāq. Con ello, se puede decir que consiguió visitar la mayor parte del mundo islámico. De Este a Oeste, cada país por el que pasa es largamente descrito: sus edificios, abundancia de bondades, sus variedades comerciales, la belleza de su naturaleza, nobleza de sus gentes; hace lo propio con los lugares santos del Islam como La Meca, Medina o Jerusalén, sin olvidarse de describir también algunos lugares sagrados de los cristianos y judíos ${ }^{14}$.

En cada ciudad por la que pasa habla de los lugares de devoción, como los mausoleos de los profetas y mensajeros (rusul wa-l-anbiy $\bar{a}^{\prime}$ ), de los compañeros del Profeta (as-șahāba) y santones (al-awliya $\left.\bar{a}^{\prime}\right)$, de las tumbas de ulemas y devotos (atqiya $\left.{ }^{\prime}\right)$, citando sus obras y mencionando algunos de sus escritos ${ }^{15}$.

12. IBN Aṣ-ṢABBĀ̈H: Minšäb al-ajbär, p. 544 .

13. Ibídem, p. 207 r. Y. Š ŠYJA: «Ba'd al-mazähir...», p. 37, habla de los años del final de la primera mitad del siglo IX H./XV J.C. y el principio de su segunda mitad, época que coincidiría con su plena juventud.

14. Entre otros ejemplos, señala del Monte de la Tora (Ŷabal Aț-Tawr) que fue el lugar en donde recibió Moisés la Tora. IBN ASS-ŚABBĀH: Minšăb al-ajbār, p. 113 r. Cuando pasa por allí el peregrino vivían en él unos monjes cristianos. Hace mención del Valle de Moisés (Wādì Müsà, ibídem, 178 r) y la iglesia de Șahiyūn, donde Jesús celebró la última Cena (ibídem, 223 r). Todas en Y. ŠAYJA: «Ba'ḍal-mazāhir...», p. 38.

15. IBN As-ṢABBĀ̄H: Minšāb al-ajbār, pp. 52, 54. Ŷ. ŠAYJA: «Ba'ḍal-mazāhir...», p. 38. 


\section{UN ESCRITOR ANDALUSÍ ANTE SUS CORRELIGIONARIOS MUDÉJARES: ENTRE EL RECHAZO, LA COMPRENSIÓN Y EL DESEO DE AYUDA}

\section{Perspectiva Religiosa. Su POSTURA PARTICUlar EN LA POlÉMiCA IS- LAMO-CRISTIANA}

I. El enfoque religioso de la obra se encuentra en las motivaciones personales del propio autor y queda señalado al principio de la misma, cuando Ibn Aṣ-Ṣabbāh, a modo de resumen, afirma que "en este libro hay ejemplos e historias para ellos [los musulmanes que quedaron en Al-Andalus tras su caída en manos de los cristianos] sobre las tierras de Allāh, sobre los países y las tribus ('ama' $i r$ ), y sobre el Islam de la nación de Muhammad -Dios lo bendiga y lo salve-".

De estas palabras se deduce que desea mostrar a sus correligionarios mudéjares cómo era la vida en el resto del mundo islámico. En suma, el conocimiento de los países del Islam, de sus peculiaridades y atractivos, busca como fin reafirmar el espíritu de los mudéjares hispanos ${ }^{16}$.

En su relato, no cesa de solicitar a Allāh su bendición para los países y reyes, bajo la bandera de la unidad y del Islam (tawhīd wa-l-Isläm). La situación de los mudéjares, bajo un estado cristiano, le hace recordar añorante la situación de cristianos y judíos bajo la administración islámica de Oriente. Señala la grandeza del Islam y la obediencia de las gentes de otras religiones a los gobernantes musulmanes, mediante el pago de la ŷizya o tributo, con sumisión: es el caso de los cristianos y judíos de Jerusalén, del rey de Constantinopla y, de su entorno, al sultán otomano ${ }^{17}$.

En el marco de este relato de exaltación de los países islámicos, fin expreso de la rihla, no deja de hablar a sus hermanos mudéjares sobre la época más importante de la historia musulmana, y de sus mejores hombres, quienes -afirma- hicieron del ŷihäd una obligación.

Contempla el mundo islámico como una unidad, únicamente rota por los jariŷ́es (al-jawāriŷ), los muŷassima (quienes creen que Dios tuvo cuerpo) y los šíî(es). No refiere división alguna del mundo islámico, ni ética, ni política, ni geográfica. Sólo lo divide según las cuatro escuelas jurídicas (madahihib as-sunniyyat al-arba'a) y afirma que las diferencias entre ellas son una suerte para los musulmanes, y que todas las sentencias de estas cuatro escuelas están basadas en el Corán y los hadices. Otra división que hace del mundo islámico se basa en las siete lecturas coránicas $\left(q i r \bar{a}^{\prime} \bar{a} t\right)^{18}$. Esto puede enten-

16. IBN Aș-ṢABBĀH: Minšāb al-ajbār, p. 272 v; 273 r. Ŷ. Š̆AYJA: «Ba'ḍal-mazāhir...», p. 37.

17. IBN AS-ṢABBĀH: Minšäab al-ajbār, p. 273 r.

18. Al hablar de ellas recuerda la lectura de las gentes del Mágreb (qirä́at ahl al-Magrib) y su perseverancia en la escuela jurídica mälikì. IBN Aș-ṢABBĀH: Minšāa al-ajbār, p. 216 r. Ý. SAYJA: «Ba'ḍal-mazāhir...», p. 39. 
derse como una generalización que apoyaría el caracter apologético y literario de la obra, mas que biográfico real.

II. De los aspectos religiosos, hay que destacar el conflicto entre dos formas de ver la espiritualidad islámica: entre el ŷihad y la devoción religiosa ('ibāda). En este dilema Ibn Aṣ-Ṣabbāḥ afirma que el ŷihad no sólo es mejor que la devoción ('ibāda), sino que llega más lejos, al decir que quien la prefiere al ŷihad puede causar un daño muy importante a los musulmanes, cometiendo un grave error. En este punto refiere una historia famosa en su época en apoyo de su argumento: resumida consiste en que la caída de Al-Andalus vino como resultado de dejar el califa almohade Al-Manșūr (gobernó entre 580-595/1184-1199) el reino a su hijo pequeño Muhammad (An-Nāșir, 595611/1199-1213), abandonando el ŷihad, para salir de viaje a Oriente y realizar la 'ibāda cerca de los Santos Lugares; allí se encontró con Ibrāhim Ibn Adham, el rey de Jurāsān, que había dejado también su reino por la misma causa.

Refiere esta historia lamentándose del acto de Al-Manșūr, e insiste que "la justicia del sultán, enfrentarse a las innovaciones (bida'), el ŷihad en el camino de Allāh, y proteger el honor de los musulmanes, son preferibles a la 'ibāda durante 70 años"19. En este sentido prefiere Al-Andalus a cualquier otro país en el que hubiera estado y convivido con sus gentes, diciendo no haber otro mejor que el reino de Al-Andalus. Quien viva en él estará feliz, y quien muera en él será mártir ("sahi $\vec{i})$, repite en numerosas ocasiones ${ }^{20}$.

Según Ibn Aș-Ṣabbāḥ la pérdida de Al-Andalus fue un golpe de la justicia divina, puesto que sus gentes "no hicieron el azaque y no conservaron la oración, ... e hicieron lo reprobable ... y se saltaron la ley de Allāh y la perdieron ... y entonces Allāh dejó caer encima de ellos a su enemigo y les arrebató a ellos su país"21. En este punto utiliza una argumentación religiosa que se repetirá desde la caída de Granada hasta nuestros días entre los musulmanes $^{22}$. Apostilla con la aleya coránica que dice "habiendo olvidado a Allāh, hace Él que se olviden a sí mismos" 23 , explicando el "olvidar" como "cambiar las palabras de Dios", "Si abrogamos una aleya o provocamos su olvido, aportamos otra mejor o semejante"24. Cuando cambiaron las gentes de Al-

19. IвN Aș-ṢABBĀH: Minšāb al-ajbār, p. 14. Ŷ. ŠAYJA: «Ba'ḍal-mazāhir...», p. 40.

20. IBN AṢ-ṢABBĀḤ: Minšäbal-ajbār, p. 21 v. Ŷ. ŠAYJA: «Ba'ḍal-mazāhir...», p. 40.

21. IBN As-ṢABĀ̈: Minšäb al-ajbār, p. 8.

22. Ver, por ejemplo, cómo en la Rihlat Al-Andalus de Hussayn Mu'nis (n. 1912) se repite en varios lugares y casi con idénticas palabras el mismo razonamiento (Rihlat Al-Andalus: Hadit ț al-firdaws al-maw' $\bar{u} d$, El Cairo, ed. Aš-Šarikat Al-Arabiyya li-ț-Tibā' wa-n-Našr, 1983, 443 pp.); Hany Muhammad EL-ERYAN: «"Viaje por Al-Andalus" de Hussain Mu'nis», Revista del Instituto Egipcio de Estudios Islámicos en Madrid, Madrid, vol. XXVI, 1993-1994, pp. 166-167.

23. Alcorán, 59: 19.

24. Alcorán, 2: 106. 
Andalus, les tornó también a ellos Allāh las gracias en desgracias, haciendo justicia de este modo, ya que anteriormente les había dado la gracia como un puro don ${ }^{25}$. Lo mismo hizo el Creador con Adán: cuando erró, le expulsó del Paraíso celeste. Al hacer las gentes de Al-Andalus lo mismo que su abuelo Adán, también cayó sobre ellos la expulsión del paraíso terreste ${ }^{26}$.

Refuerza sus argumentos hablando de la gente de Trípoli, a quienes Allāh castigó con el hambre y el miedo por sus muchos pecados (d्रunüb-hum); también los compara con las gentes de La Meca cuando pecaron "Y los hizo probar Allāh el hambre y el miedo por culpa de quienes lo hicieron"27.

III. Entre los juicios religiosos que el prof. $\hat{Y}$. Šayja ha escogido de Ibn Ass-Ṣabbāh destaca lo que escribió sobre la aplicación de la pena de cortar la mano al que roba. Como en otros aspectos, en éste es también relativamente flexible. Dice que se debe aplicar la conocida pena islámica de cortar la mano al que roba, pero que 'Umar Ibn Al-Jatțāb en el año de la gran hambruna no la aplicó. Por contra en época del autor, en Alejandría aplicaron la pena de muerte a quien había robado un huevo; afirma que esto es exceder la pena islámica con crueldad y sin sentido. Pero matiza luego que, tras ver lo que les pasó a los peregrinos en el Monte 'Arafāt y en Minà, donde comprobó la osadía e insistencia de los ladrones, quizás lo visto en Alejandría fuera una forma de parar a esta gente. Pero aclara que esto es sólo recomendable en los países islámicos.

IV. Su opinión acerca de la crucifixión de Jesucristo es acorde al Islam: "No le mataron, ni le crucificaron, sino que eso les pareció a ellos" 28 . A su llegada a Alejandría le cuentan a Ibn Aṣ-Șabbāḥ un relato sobre Euclides el griego (Uqlīs Al-Yūnānīi), uno de los hijos del filósofo Aristóteles -el constructor de Alejandría, según dice-: la madre de Euclides tenía un fragmento del lignum crucis, y una noche soñó Euclides que él y su madre estaban sirviendo a esa cruz. Fue el primero que adoró la cruz, siguiéndole luego todos lo que tuvieron que sufrirlo -según refiere-.

Esta narración influyó sobre el espíritu de Ibn Aṣ-Ṣabbāḥ, pues declara que se volvió hacia los libros sagrados judíos y sus noticias (suponemos que se refiere a los de los cristianos), los cuales leyó. Ello a su vez le indujo a la duda hacia la doctrina islámica de la Ascensión de Jesucristo (raf'a 'Isà), induciéndole Satán a creer en contra de las doctrinas del Islam, y confesando que estuvo a punto de abandonarlo, si no fuera porque le vino la luz del Alcorán. Entonces recordó lo que dicen las aleyas coránicas y se tranquilizó. Afirma seguidamente que los cristianos están disculpados en su extravío

25. IBN As-ṢABBĀH: Minšāb al-ajbār, p. 9 r. Ŷ. Š

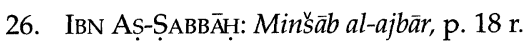

27. Ibidem, p. $73 \mathrm{v}$.

28. Alcorán, 4: 157. 
(dalāli-hum) pues lo que se cuenta en este relato sucedió durante la noche. Allāh envió esa noche una neblina (al-gamām), confundiéndose todo, y las voces y las cosas se tornaron parecidas, de ahí vino la confusión.

Evita Ibn Aș-Sabbāh entrar a pronunciarse más directamente sobre la ascensión -según los musulmanes- o la crucifixión -según los cristianos-, según afirma por temor a la gente $\left(a l-{ }^{\prime} \bar{a} m m a\right)$. Concluye este relato dando gracias a Allāh por tener el bendito Alcorán como guía ${ }^{29}$.

V. Otro punto que también resalta es el que habla de la realización del haŷy a Jerusalén. Afirma Ibn As-Sabbāh que para quien no pueda ir a La Meca (al-haŷy $a \underline{d}-\underline{d} a h \tilde{a} b)$, es suficiente llegar hasta Jerusalén, lo cual denomina como "la peregrinación necesaria (al-haŷy ad-darüra)" -para quien no pueda realizarla a La Meca-, afirmando que esto es lo que algunos musulmanes hacían. Lo reitera afirmando que él la realizó y vio que era suficiente para algunos musulmanes débiles en economía o en salud ${ }^{30}$.

\section{PERSPECTIVA EDUCATIVA}

I. Ibn As-Sabbāh dictó su rihla al final de su vida, estando en tierras "externas al $\dot{\bar{D}} \dot{\bar{a}} \mathrm{r}$ Al-islam", habiéndose quedado bajo el dominio cristiano con la minoría mudéjar, una población islámica amenazada en su identidad religiosa y civilización. El deber de la hermandad religiosa le obliga a prestar servicios a esta minoría, ya que la mayor amenaza para ellos era la carencia de enseñanzas religiosas ( $t a$ 'ällim ad-din), y como consecuencia, el peligro de que se cristianizaran voluntaria o involuntariamente. Por eso el autor busca afianzar algunos aspectos religiosos y reforzar las creencias de los mudéjares mediante su relato.

Habla el autor de las dificultades de la vida para los mudéjares en la Península y de su ignorancia (yahl), que los mantiene "sordomudos" (summ bukm), según su gráfica expresión, por esto insiste Ibn As-Sabbāh en la materia religiosa, recordándoles lo más importante de su enseñanza y ritos, como el hâŷy y la 'umrā'.

Tiene por ello esta rihla un marcado aspecto educativo. Primero, al resaltar continuamente los testimonios que aporta mediante aleyas coránicas o con la sunna del Profeta. El autor buscaba que su obra contuviera no sólo información sobre las grandezas de los países islámicos, sino las aleyas y hadices que puede necesitar un buen musulmán para su práctica religiosa cotidiana. No hay página alguna sin una o más menciones del Alcorán o de la sunna del Profeta; algunas veces, incluso, avanza la interpretación, explicándola para acercarla al lector ${ }^{31}$.

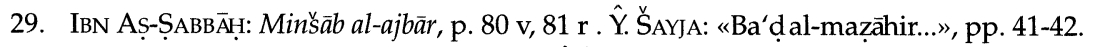

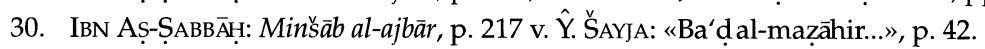

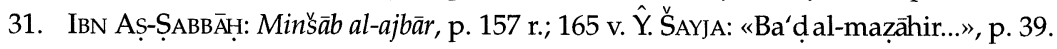


En varias ocasiones explica deberes religiosos del musulmán tales como la oración, el azaque, o la peregrinación (haŷy). Con respecto a este último punto, el autor de la rihla describe todos los pasos de la 'umra y el haŷy con gran claridad ${ }^{32}$.

II. En otro de los aspectos que insiste es en la unidad del Creador y la fe, sin comentarios. Sólo es suficiente para el hombre que comprenda sin la ayuda de nadie. La imagen de la fidelidad hasta que ve la unicidad del creador, sin dudarlo. Afirma que cada aspecto de la religión puede imitarse, a excepción del conocimiento de la unicidad del Creador. A esto tiene que llegar el creyente por sí mismo, ya que para el conocimiento de la unicidad de Allāh no es suficiente con la imitación, sino que "en la imitación hay infidelidad completa (Kufr mahd)"33.

III. Por otro lado, evita entrar en explicaciones sobre la realidad del Mesías (Al-Masīh), esquivando el asunto de la Crucifixión y de la Ascensión de Cristo, por temor a que sus propias dudas pudieran interferir en la fe de los mudéjares, o-como se dijo ya- a que no le entendieran adecuadamente. Recoge las aleyas que niegan la crucifixión del Mesías y aseguran su ascensión al cielo, junto al "Dios de los dos mundos".

IV. El sentido educativo en esta relación de viaje también aparece a través de las ilustraciones que contiene el manuscrito sobre los lugares sagrados del Islam, como la mezquita del Profeta en Medina, la mezquita de AlAqșà en Jerusalén y la mezquita Haram Al-Jalī ${ }^{34}$. Ligado con lo anterior, en su relación también se describen los lugares santos cristianos.

\section{PERSPECTIVA SOCIAL}

I. El peregrino almeriense, doliéndose por la pérdida de Al-Andalus, reitera su ruego a Allāh para que otorgue su protección a los musulmanes, especialmente a quienes se quedaron en Al-Andalus bajo la dimma (sic) ${ }^{35}$.

De igual modo le pide que perdone a quienes pudiendo salir no lo han hecho. $Y$ en este punto se incluye el propio autor, ya que él mismo había viajado por casi todo el mundo islámico, para al final de su viaje, volver a vivir a su tierra de origen, ya bajo el dominio de los cristianos. En su criterio, la estancia en Al-Andalus de los mudéjares que pudiendo salir no lo han hecho

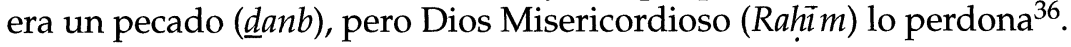

32. IвN AṢ-ṢABBB̄̄H: Minšāb al-ajbār, p. 116 v.; 117 r.

33. Ibídem, $271 \mathrm{v}$.

34. Ibídem, pp. 121 v, 122 r, 170 v, 202 v, 198 v.

35. Utilización islámicamente errónea del concepto; éste se aplica a la ahl ad-dimma (cristianos o judíos) bajo la autoridad del Islam, no al revés. Cfr. E.I. ${ }^{2}$, s.v., II, pp. 234-238.

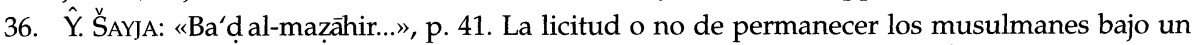
gobierno cristiano (tema no contemplado por la normativa islámica) fue en su momento 
II. Aparecen los cristianos (an-nasāa $\bar{a})$ en numerosas ocasiones a lo largo de su relación de viaje, bien para hablar de su extravío, o para manifestar su anhelo de ponerlos bajo el pago de la capitación (ŷizya) al gobierno islámico, con lo que ello implica de sometimiento al Islam.

No hay muchos datos sobre la relación de Ibn Ass-Şabbāh con los cristianos y los que refiere entran más dentro del campo de lo anecdótico, rayano en la picaresca. Cuando habla de los cristianos peninsulares, más que para aludir a su conquista de Al-Andalus, es para hablarnos de su relación con ellos (a pesar su carácter de mudéjar cuando dicta su rihla).

De su relación con los cristianos de Oriente resalta, en varios lugares de su obra -como se ha referido- el carácter de dimmỉes de éstos, estatuto que no deja de anhelar para los hispanos. Fuera de esto, afirma también que los cristianos abundan en Beyrut, que tuvo una discusión sobre el comercio con uno de ellos, y que le gustó su punto de vista ${ }^{37}$.

En el Bilād Aš-Šam (Siria) nos refiere cómo entabló amistad con unos monjes (ruhbān) y éstos le pidieron que les describiera la Ka'ba, cosa que hizo; pero luego le pidieron que orara $\left(y^{\prime} d^{\prime} \bar{u}\right)$ para ellos. Quedóse pensativo sobre cómo hacerlo, pero al final encontró el modo, diciendo: “iOh Dios! Su gente [los cristianos] está entre la [gente] de la mejor de las religiones"; ellos, complacidos, dijeron "Amén", pero sin entender el doble sentido de la frase ${ }^{38}$ También en esta región halló una mujer cuya belleza le gustó; le confió ella que era cristiana y le dio de comer pan y leche al peregrino, pidiéndole que rogara ('an yad' $\bar{u}$ ) por ella y sus hijos, lo cual hizo de igual modo que con los monjes ${ }^{39}$.

Finalmente, en la misma línea, refiere que entró en Constantinopla cuando todavía estaba bajo el dominio bizantino (fue conquistada por los turcos el 29 mayo 1453). Afirma que tenía el deseo de visitar la iglesia de Santa Sofía (kanisat $\bar{A} y \bar{a}$ Șuffiya $)$. Entró en ella disfrazado, y preguntó sobre algunas cosas

objeto de un amplio debate en el mundo islámico, y dio origen a varias consultas a jurisperitos musulmanes acerca de ello. Se trata de un tema muy estudiado, y sobre las fatā $\bar{a} \bar{a}$ de Az-Zayyātì-Al-Wanšarîsĩ y Al-Māzarì pueden consultarse H. BuZINEB: «Respuestas de jurisconsultos maghrebíes en torno a la inmigración de los musulmanes hispánicos», Hesperis-Tamuda, Rabat, ed. Université Mohammed V, vol. 26-27, 1988-1989, pp. 54-66. Inteligente planteamiento del problema en F. DACHRAOUI: «Integration ou exclusion des minorités religieuses. La conception islamique traditionnelle», L'expulsió dels Moriscos. Conseqüències en el món islàmic i en el món cristià. Congrés Internacional 380è Aniversari de l'Expulsió dels Moriscos. Sant Carles de la Ràpita. 5-9 de desembre 1990, Barcelona, ed. Departament de Cultura de la Generalitat de Cataluña, 1994, pp. 195-203.

37. Y. Š ŠYJA: «Ba'ḍal-mazāhir...», p. 42.

38. La ambigüedad de "Su gente está entre la de la mejor de las religiones" sería entendida por los cristianos como una alabanza a su gente y a su religión, mientras que para los musulmanes se entendería una alusión al hecho físico de vivir los cristianos "entre" musulmanes, con lo cual "la mejor de las religiones" sería la islámica. IBN Aș-ṢABBĀḤ: Minšāb al-ajbār, pp. 205 r, 205 v y 207 r. Ŷ. ŠAYJA: «Ba'ḍal-mazāhir...», p. 43.

39. Ibídem. 
prendidas de su cúpula, sabiendo por un árabe cristiano que eran la camisa de José (qamiș Yusuf), el manto de María (ridā' Miryam) y el vestido de Aarón (tawb Harūn); todos ellos eran blancos; había un cetro ('așa $\left.\bar{a}^{\mathrm{n}}\right)$, que era el báculo ('ukkāz) de Jesús, y estaba también la vajilla (al-ānìya) de cobre en la cual comía Jesús la al-basīsă $\bar{a}^{40}$ en sus viajes y excursiones.

Pero el religioso reponsable de la iglesia le reconoció por mirar atentamente estas cosas; encolerizado, le describió como el peor de los musulmanes, entrando seguidamente algunos hombres armados (al-ŷanwiyyin $)^{41}$ que preguntaron a Ibn Aș-Sabbāh sobre sus creencias, aunque en lengua franca (lisān al-ifrānŷ). Aseguróles el autor su creencia en Jesús y en que con Jesús se había revelado Dios "en el libro"42, que era el espíritu de Dios ( $r \bar{u} h$ Allāh), y que su palabra la había hecho llegar a la Virgen María (Miryam al-'A $\left.\underline{d} r \bar{a}^{\prime}\right)^{43}$. Tradujeron los soldados al sacerdote estas palabras, y le dijeron que era un hombre virtuoso. Pero el sacerdore entendió la picardía de Ibn Aṣ-Șabbāh, y no le creyó, por lo cual hubo una discusión entre ellos ${ }^{44}$. Les dejó el peregrino que disputaran, yéndose a otro lado de la iglesia para observar las estatuas de cobre de Constantino, el hijo de Heraclio (Qustanțīn Ibn Hiraql).

III. De los ejemplos aducidos se pueden sacar varias conclusiones. Una primera, evidente, su anhelo del retorno de los cristianos al estatuto de la dimma del Islam o lo que es igual, que la situación política volviera a los musulmanes el gobierno de Al-Andalus.

Una segunda, es que que estos ejemplos, fuera de lo pintoresco y anecdótico, tienen como factor común la picardía de la que se vale este musulmán para contemporizar con los cristianos, obteniendo de ellos lo que desea, y evitando los motivos de discordia religiosa.

Aporta, por tanto, a sus lectores mudéjares experiencias personales que puedan ayudarles a salir de situaciones apuradas, cada vez más frecuentes entre cristianos y musulmanes. El método empleado es la consciente búsqueda de la ambigüedad, para así moverse en un terreno lingüístico, concep-

40. Pastel de sémola y almendras, tradicional y típico de Egipto, y del Próximo Oriente.

41. Literalmente serían "espaderos". Palabra de origen beréber, yanw $\vec{\imath}$, cuyo significado es "sable muy largo, espada", según R.P. DOZY: Supplément aux Dictionaires Arabes, Leiden-París, ed. E.J. Brill / G.P. Maisonneuve et Larose, 1881, I, 255.

42. Frase ambigua. Los cristianos entenderían que Jesús era la revelación de Dios min Kitäb, en la Escritura, el Evangelio, mientras que para los musulmanes el sentido sería que Dios se había revelado acerca de él min Kitāb, en el libro por excelencia, el Alcorán.

43. Literalmente "su palabra la hizo llegar/la echó sobre la Virgen María". Nueva frase ambigua en que los cristianos entenderían lo que dicen los Evangelios respecto a la Anunciación, mientras que los musulmanes verían a María como cumplidora de los designios divinos.

44. Los soldados entendieron sus palabras árabes en el sentido genérico que tienen, pero al traducírselas al griego al sacerdote debió quedar en evidencia su significado equívoco, que por otro lado los soldados no tenían por qué -o no supieron- verlo como tal. 
tualmente muy medido, en que sin traicionar las concepciones islámicas, los cristianos vean una voluntad de acercamiento. En el fondo no es sino una relación basada en el engaño (o al menos esto es lo que se deduce de los fragmentos publicados por el profesor $\hat{Y}$. Šayja).

\section{LUGAR DE LA OBRA DE IBN Aṣ-ṢABBĀH DENTRO DEL GÉNERO RIḤLA}

\section{LA RIỴLA, UN GÉNERO LITERARIO Y GEOGRÁFICO DEL OCCIDENTE MUSULMÁN}

El concepto del viaje es inherente a la civilización arábigoislámica, y la peregrinación a la Meca, como precepto religioso siempre ha movilizado a gran número de musulmanes de todo el orbe islámico. Como género, la rihla hiy $\bar{a} z i y y a$ es una producción específica de los musumanes del Occidente musulmán ${ }^{45}$. El motivo surge de la lejanía del Al-Andalus y el Mágreb a los santos lugares del Islam. La distancia, que tanto separa, requiere una especial disposición por parte del peregrino, siendo habitual que en el viaje se invirtieran varios años, ya que se aprovechaban las ciudades por las que se pasaba para residir un tiempo en ellas, aprender o conocer a sus personajes y sabios más notables, etc., con lo que el haŷy se convierte en un "proceso iniciático" cuyo final es en La Meca. Durante días, ingentes masas de peregrinos venidos de todos los rincones del mundo proclaman la unidad de la fe musulmana. Es lógico, por tanto, que a la vuelta de la peregrinación cuenten sus experiencias, y que las dejaran por escrito.

Ya se conocen las primeras relaciones de la peregrinación a la Meca desde mediados del s. X/IV, en que hay noticia de la rihla de Ibn al-Qallās (m. 337/948) ${ }^{46}$, pero hasta el s. VI/XII no se conocen ejemplos notables.

Dejando aparte los tres fragmentos que se conservan de los diversos viajes de Abū Haămid Al-Garnāṭi (473-565/1080-1169), llenos de elementos

45. Regis Blachère y Henry Darmaun: Geographes arabes du Moyen Age, París, ed. Librairie C. Klincksieck, 1957, pp. 315 y ss. Ver igualmente sobre la rihla como género literario $\mathbf{M}^{\mathrm{a}}$. Jesús RUBIERA: Literatura Hispanoárabe, Madrid, ed. Mapfre, 1992, pp. 224-229, y como género geográfico: Muammad HADJ-SADOK: "Le genre "Rih'la"», Bulletin d'Études Arabes, Alger, no. 40, anné 8, 1948, pp. 195-206; Hussayn Mu'NIS: Al-Ŷ́ugräfiyya wa-l-Ŷugrāfiyyìn fi-l-Andalus, Madrid, ed. Instituto Egipcio de Estudios Islámicos, 1967, 723 pp. Michel Karl LENKER: The importance of the Rihla for the islamization of Spain, Pennsylvania, ed. University of Pennsylvania, 1982, 388 pp., entre otras muchas obras que podrían citarse.

46. Primer personaje andalusí del que se conoce su Rihla, noticia, Manuela MARÍN: «Rihla y biografías de Ibn al-Qallās (m. 337/948)», Homenaje al Profesor Fórneas Besteiro, Granada, ed. Universidad de Granada (en prensa). 
del género de las "maravillas" ('ây $\bar{a}$ ' $i b)^{47}$, se consideran como los modelos "canónicos" del género la riḥla de Ibn Ŷubayr (m. 614/1217) ${ }^{48}$ y la de Ibn Battūta (m. 779/1377) ${ }^{49}$. La primera es la arquetípica; refiere con gran detalle el itinerario y las vivencias del viajero, así como las poblaciones por donde pasó, describiendo con gran detalle tanto los Santos Lugares del Islam, como los ritos y oraciones del haŷy. En este aspecto la relación de viaje de Ibn Bațtūta copió no sólo este modelo, sino también algunos pasajes relativos a los ritos y la descripción de La Meca. El resto de relatos de peregrinación posteriores ya son muy parecidos. También algunos moriscos.

\section{EL GÉNERO RIḤLA ENTRE MUDÉJARES Y MORISCOS}

Este género literario árabe, con una personalidad y evolución tan propias, también ofrece algunos ejemplos en las épocas mudéjar y morisca. En el sentido general del término riḥla, como relación de viaje de un personaje, de cualquier viaje, se conocen algunos ejemplos notables. Posteriores a la expulsión de los moriscos, hay varias guías de viaje, concisas y someras, que refieren el itinerario de retorno de algunos de ellos a España, por motivaciones

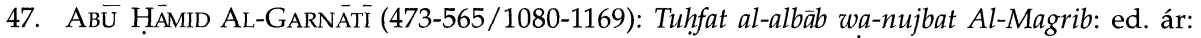
Gabriel FerRAND: Le Tuhfat al-albāb de Abū Hạamid Al-Andalusì al-Ǵarnātí. Edité d'après les mss. 2167, 2168, 2170 de la Bibliothèque Natonale et le ms. d'Alger, París, ed. Imprimerie Nationale, 1925, 304 pp.; trad. esp. de Ana Ramos CAlvo: Abū Hāamid al-Ǵarnātì (m. 565/1169). Tuhfat Al-Albäb (El regalo de los espíritus), Madrid, ed. C.S.I.C. / I.C.M.A., 1990, 144 pp. Y su $A l-M u^{\prime} r i b$ 'an $b a^{\prime} d$ ' $a \hat{y} \bar{a}$ ' $i b$ Al-Magrib, ed. ár, trad. esp. de Ingrid BEJARANO EsCAMILLA: Al-mu'rib 'an ba'd 'aỹa'ib Al-Magrib. Elogio de algunas maravillas del Magrib por Abū Hamid Al-Garnatì (m. 565/1169), Madrid, ed. C.S.I.C., 1991, 306 pp.; otro fragmento es el que editara y tradujera en César E. DUBLER: Abū Hãmid el Granadino y su relación de viaje por tierras euroasiáticas (texto árabe, traducción e interpretación), Madrid, ed. Imp. y Editorial Maestre, 1953, 425 pp.

48. Ibn Ŷbayr (m. 614/1217): Rihla. ed. ár: W. WRIGHT: The travels of Ibn Ibn Jubayr, ed. from a Ms. in the University Library of Leyden, Leiden, ed. E. J. Brill, 1852; trad. fr. Maurice GAUDEFROY-DemombYNES: Ibn Jubayr. Voyages, París, ed. Librairie Orientaliste Paul Geuthner, 1965, 4 vols.; trad. esp. Felipe MaÍllo SALGado: Ibn Ŷubayr. El siglo XII ante los ojos, Barcelona, ed. del Serbal, 1988, 431 pp.

49. IBN BATṬUTA (m. 779/1377): Tuhfat al-nuzzāor fì garā'ib al-amṣar wa-l-'ayấ'ib al-asfär, ed. ár, trad. fr.: C. DEFRÉMERY; B.R. SANGUINETTI, París, 1853-58, 4 vols.; esta edición es reproducida tal cual en algunas ed. ár. orientales, como por ej. la de Beirut, 1960. Nueva ed. ár. H. A. R. GIBB: Ibn Battuta's Travels in Asia and Africa, London, 1929. Sobre ésta la Hakluyt Society inició una nueva traducción integral largamente anotada: The Travels of Ibn Battuta, I-III, Cambridge 1958-71. Otras traducciones parciales son la alemana: H. von MzIK: Die Reisen des Arabers Ibn Batuta durch Indien und China, Hamburg, 1911, y la trad. ingl.: M. HusAIN: The Rehla of Ibn Battutta (India, Maldive Islands and Ceylon), Baroda 1953. Trad. esp., estudio: Serafín FANJUl y Federico ARBós: Ibn Battūta. A través del Islam, Madrid, ed. Editora Nacional, 1981, 796 pp. Trad. ital.: Francesco GABRIELLI: «I viaggi di Ibn Battuta», Poesia $e$ aventura nel Medioevo. Shànfara-Sindibàd-Ibn Battuta, Firenze, Casa Editrice Le Lettere, 1988, pp. 113-560. Un bien informado volumen de conjunto sobre el autor y su obra es el de H.F. JANSEN: Ibn Batouta, "le Voyageur de l'Islam" (1304-1369), Bruxelles, 1948. 
diversas: bien por nostalgia, para recuperar pertenencias abandonadas en sus tierras de origen, etc. ${ }^{50}$. Otro texto es el Nâssir Ad-Dīn 'alà l-qawm al-käfirīn de Ahmad Ibn Qāsim Ibn Ašs-Sayj Al-Hayâāî Al-Andalusín ${ }^{51}$ relato del s. XVIXVII en que se refiere la embajada a Francia y Holanda de este morisco y una serie exposiciones en la línea de la polémica islamo-cristiana.

Ahora bien, en cuanto a los relatos de la peregrinación a los santos lugares del Islam, contamos con dos pararelos notables. El más antiguo se corresponde a los textos de dos mudéjares editados por Míkel de Epalza. Son dos relatos de peregrinación a Oriente: del morisco aragonés Ibn Fath Ibn Abỉ Rabī'a, y un musulmán fāsí, relatos fechados en 1395 y $1407-1412^{52}$, anteriores en cincuenta y cuarenta años, por tanto, al viaje de Ibn Aṣ-Ṣabbāḥ. El primero es una traducción en prosa del original árabe y el texto del cautivo marroquí es una urŷuza; ambos fueron traducidos al castellano en el siglo XVI. El primero es más una guía clásica del peregrino a La Meca (no a

50. Ver al respecto los viajes estudiados por Luce LóPEZ-BARALT y Awilda IRIZARRY: «Dos itinerarios secretos de los Moriscos del siglo XVI (Los manuscritos aljamiados 774 de la Biblioteca Nacional de París y T-16 de la Real Academia de la Historia)", Homenaje a Álvaro Galmés de Fuentes, Oviedo-Madrid, ed. Universidad de Oviedo/Editorial Gredos, vol. II, 1985, pp. 547-582, y SÁNCHEZ ÁlvAREZ, Mercedes: El manuscrito misceláneo 774 de la Biblioteca Nacional de París, Madrid, Editorial Gredos (C.L.E.A.M.), 1982.

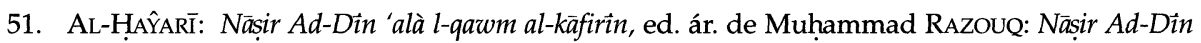

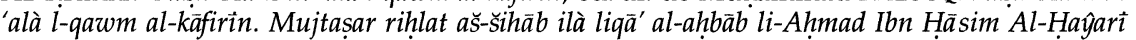
Al-Andalusì (Afūqāyy), Dằr Ai-Baydăà', ed. Manšürằt Kuliyyat al-Ādāb wa-l-'Ulūm al-Insāniyya, 1987/1407, 167 pp. Está siendo preparada una nueva edición de su texto en Leiden por los profs. Van Konningsveld, Samarrai y G. Wiegers. Fragmentos relativos a Francia y Al-Andalus han sido editados por Cl. Sarnelli Cerqua, quien también ha estudiado en profundidad la obra en numerosos trabajos: Clelia SARNell CERQUA: «La fuga in Marocco di aš-Šihāb Ahmad al-Ḥağarì al-Andalusì», Studi Magrebini, Nápoles, vol. I, 1966, pp. 215-229 + XVIII pis.; id., «Un voyageur arabo-andalou au Caire au XVIIème. siècle: al-Shihāb Aḥmad al-Ḥ̣ağarì», Colloque International sur l'Histoire du Caire, El Cairo, 1969, pp. 103-106; id., "Al-Hağarî in Andalusia», Studi Magrebini, Nápoles, vol. III, 1970, pp. 161-203; id., "Lo scrittore ispano-marocchino al-Hağarî e il suo Kitāb Nāșir ad-Dîn», Atti del III Congresso di Studi arabi e Islamici (Ravello, 1966), Nápoles, 1967, pp. 595-614 + X pls. Trad. fr.: "L'ecrivain hispano-marocain al-Ḥağarî et son Kitāb Nāssir ad-Dîn», en M. EPALZA y R. PETIT: Études sur les Moriscos andalous en Tunisie, Madrid, 1973, pp. 248-257; id., "Al-Hạağarì en Rouen e a Parigi», Studi arabo-islamici in onore Roberto Rubinacci nel suo settantesimo compleanno, Napoli, ed. Istituto Universitario Orientale, vol. II, 1985, pp. 551-568; id., «La contribution d'Al-Hağarì a l'histoire d'Al-Andalus», Revista del Instituto Egipcio de Estudios Islámicos en Madrid, Madrid, nº. 23, 1985-1986, pp. 113-119; id., "Al-Hağarî en France», Actas del III Simposio Internacional de Estudios Moriscos. Las prácticas religiosas de los moriscos andaluces (1492-1609), Zaghouan (Túnez), ed. C.E.R.O.M.D.I., 1989, pp. 161-166. Estudio de la rihla como género magrebí, y lugar de Al-Hayâarî̀ en él: Abdelmajid KADDOURI: «Images de l'Europe dans un genre d'écriture marocaine: "La Rihla"», Les Cahiers de Tunisie, Túnez, Tome XLIV, $\mathrm{n}^{\circ}$. 157-158, 1991, pp. 123-134.

52. Míkel de Epalza: «Dos textos moriscos bilingües (árabe y castellano) de viajes a Oriente (1395 y 1407-1412)", Hesperis-Tamuda, Rabat, vol. XX-XXI, 1982-1983, pp. 25-112. Ver igualmente Míkel de EPALZA: «Rites musulmans opposés aux rites chrétiens dans deux textes de morisques tunisiens: Ibrahim Taybili et Ahmad Al-Hanafi», Actas del III Simposio Internacional de Estudios Moriscos. Las prácticas religiosas de los moriscos andaluces (1492-1609), Zaghouan (Túnez), ed. C.E.R.O.M.D.I., 1989, pp. 71-74. 
Medina) que una relación de viaje erudita y detallada, ya que se centra en el ritual y oraciones más que en otras descripciones.

Un segundo ejemplo apareció en el fondo de libros de Almonacid de la Sierra. Se trata de las Coplas del Alhichante de Puey Monçón; éstas, en forma de octavas, refieren -como en los casos precitados- el viaje de un peregrino originario de Pueyo de Monzón, en el Valle del Cinca, realizado hacia el $1603^{53}$. Estas "coplas" -como las denominó su editor-narran con detalle los ritos religiosos en torno al haŷy y la ' $u m r \bar{a}$ ', describiendo también los santos lugares, en sintonía con el texto publicado por M. de Epalza. También este texto es aragonés, pero en el caso que nos ocupa el relato es de comienzos del s. XVII.

Con los dos ejemplos citados, la riḥla de Ibn Aṣ-Ṣabbāh tiene en común el carácter de exaltación del Islam, la inclusión de descripciones de lugares y rituales, y la voluntad de acercamiento religioso para unos lectores, mudéjares o moriscos, alejados, no sólo físicamente del Hị̂āz, sino de la misma posibilidad de realizar la peregrinación al mismo.

Como diferencias notables hay que apuntar su origen, en un entorno mudéjar, castellano y almeriense, no ha mucho islámico. Más importante es la forma: el de Ibn Aṣ-Ṣabbāh, se encuentra en prosa y en árabe, aunque poco culto y con dialectalismos.

\section{El REINO DE GRANADA EN LA RIHLA DE IBN AșȘABBĀH}

Finalmente, presentamos la traducción de dos dos textos en que se ve la perspectiva que transmite del Reino de Granada. En uno primero nos dice:

“Llegué a la ciudad de Granada, que es la sede del reino [de los Banū lAhmar]. Es una ciudad de bellas construcciones y hermosos rincones, la cual pende de la montaña sobre la que se encuentra la Alhambra, es decir, la residencia del sultán [Dār As-Sulțân]. Ciudad generosa, en ella hay toda clase de cosas, abundan el agua, los sembrados, los cultivos, las huertas [al-basātīn], las verduras [judra' $\bar{a}^{\prime}$ y tiene muchas edificaciones: [todo ello] en ciudades y en fortalezas. Es la capital de su reino [Där mamlakati-hi] y entre sus gentes: hay rectitud en la administración de justicia; son correctos en las ventas y las compras, respetan lo lícito [halāl] y lo reprobable [harām]. En ella no hay ni hambrientos ni desnudos, ni quien proteste, ni quien llore, y esto indica la justicia y la bondad; en sus gentes reside la bondad y la piedad [șatāh]. Me entristece

53. Editadas por Mariano PANO y RUATA: Las coplas del peregrino de Puey Monçón. Viaje a La Meca en el siglo XVI, Zaragoza, Tip. de Comas Hermanos, 1887, 303 pp. Ver igualmente el estudio de Ramón ZúNIGA LóPEZ: «Las coplas del alhichante de Puey Monçón (Peregrinación a la La Meca de un morisco aragonés a finales del siglo XVI)», Miscelánea de Estudios Árabes y Hebraicos, Granada, ed. Universidad de Granada, vol. XXXVII-XXXVIII, 1988-1989, pp. 449-479. 
la pérdida de la península de Al-Andalus [ŷazirat Al-Andalus], y doy gracias a Dios porque dejó una parte de la península de España [Ŷazirat Isbäniyya] bajo el poder de los musulmanes ¡Gracias a Dios! Doy también gracias a Dios cuando le irrita alguna de sus critauras, ya que abunda su paciencia, su generosidad y su bondad; su gracia y clemencia exceden a su enfado y coraje" ${ }^{25}$.

Más que del Reino, habla propiamente de la ciudad de Granada y de sus gentes. Frente a los detalles que aporta de los lugares que visitó, con ilustraciontes incluidas y algunas anécdotas personales, esta imagen de la ciudad es una desripción idealizada. Aunque utiliza un léxico común a los tratados geográficos árabes, se trata de una relación casi arquetípica de bondades urbanas y humanas, transmitiendonos un ambiente casi ideal.

En otro texto aporta otro matiz diferencial, que nos da la clave.

“Dice Ibn Aṣ-Ṣabbāh: entré en los países, y conviví con los devotos [al'ubbād, de Dios, los musulmanes]. No vi [otro] superior en bondad[es] que en reino de Al-Andalus. Quien vive en él es feliz, quien muere en él es santo [ $\left.{ }^{\vee} a h \vec{\imath} d\right]$. Ello demuestra que aquella tierra es lo último que les resta a los puros [sälihiyyïn]. Sus pobladores son los últimos puros" ${ }^{\prime 55}$.

Se trata de una mirada hacia el pasado, separando una realidad que idealiza (y eso que la conoció bien), de la conducta desviada de sus habitantes; construye una imagen literaria acorde con las que hablan del "paraíso perdido" de Al-Andalus, un Al-Andalus que todavía está vivo, aunque sólo ya en la memoria, cuyo recuerdo desea fijar en positivo, porque la sociedad y la historia ya comienzan a desvanecer esa imagen.

\section{COLOFÓN PROVISIONAL}

Éstas son algunas de las conclusiones que es posible extraer del estudio de la obra que nos ocupa, que hay que entender como provisionales, hasta el momento en que podamos consultar su edición crítica completa, y no fragmentos escogidos.

Es enorme la gama de posibilidades, interrogantes y las inquietudes que suscita la riḥla de Ibn Aṣ-Ṣabbāh. Tomaremos un ejemplo concreto para ilustrarlo. Escribimos enviándole la traducción del texto en que el viajero habla de su experiencia en la basílica de Santa Sofía de Constantinopla al experto bizantinólogo Juan Nadal Cañellas, y le pedimos su parecer. En amable carta nos respondió que -de acuerdo a lo referido- el viajero demuestra que jamás estuvo en Constantinopla, la cual conocería por algunas descripciones que le

54. IBN Aș-ṢABBĀḤ: Minšsāb al-ajbār, pp. 17 r, 17 v; Ŷ. ŠAYJA: «Mamlaka Banì l-Aḥmar...», pp. 297298.

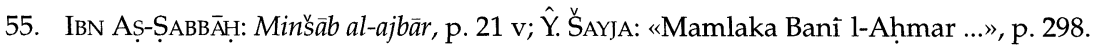


hicieran algunos viajeros árabes; y nos justifica su juicio basándose en una serie de argumentos que condensamos: en primer lugar, Ibn Aṣ-Ṣabbāḥ se figura que Santa Sofía es una iglesia de reducidas dimensiones, de la cual se podrían colgar las "reliquias" de las que habla (nada más opuesto de la realidad); por otro lado los bizantinos jamás han colgado las reliquias, sino que las guardaban cuidadosamente en cofres de material precioso, en una sacristía especial destinada a guardar ornamentos y vasos sagrados. $Y$ en segundo lugar, la mención de las estatuas de Constantino, en plural, y de cobre, dentro de una iglesia, de acuerdo con las fuentes bizantinas es lo más alejado a la realidad ${ }^{56}$.

En la misma línea argumental, el carácter generalizante de los textos analizados, escaso en detalles (fechas, nombres, topónimos, etc.) es, cuando menos, sospechoso; más si lo comparamos con las detalladas obras de Ibn Ŷubayr o Ibn Battūta.

Lo atípico y extraño de la narración de su visita a Santa Sofía de Constantinopla y lo general de sus descripciones de los lugares por los que pasa (como por ejemplo Granada) sugiere que esta obra es más bien una elaboración literaria con un fin educativo y apologético. $\mathrm{O}$ es el resultado de la débil retentiva de un anciano y su memoria sólo habría guardado o resaltado aquellos aspectos o anécdotas que dejaron huella en su ánimo y que van encaminados a este fin apologético.

Como colofón, sólo queda señalar que se trata de un texto puente entre dos mundos. Por ello adolece y participa de las peculiaridades del final de al-Andalus, y ya empieza a sentar las bases para la configuración de una nueva literatura mudéjar/morisca de viajes, todavía en árabe, puesto que sus receptores aún conservan esta lengua.

56. El Profesor J.S. Nadal nos ha aportado otros elementos más concretos que siguen rebatiendo la verosimilitud del texto, pero abundan en el mismo sentido apuntado. Reservamos estos argumentos y otras posibles interpretaciones alternativas del texto para estudios ulteriores a la edición de la obra en su totalidad. 


\section{SHARQ AL-ANDALUS Estudios Mudéjares y Moriscos}

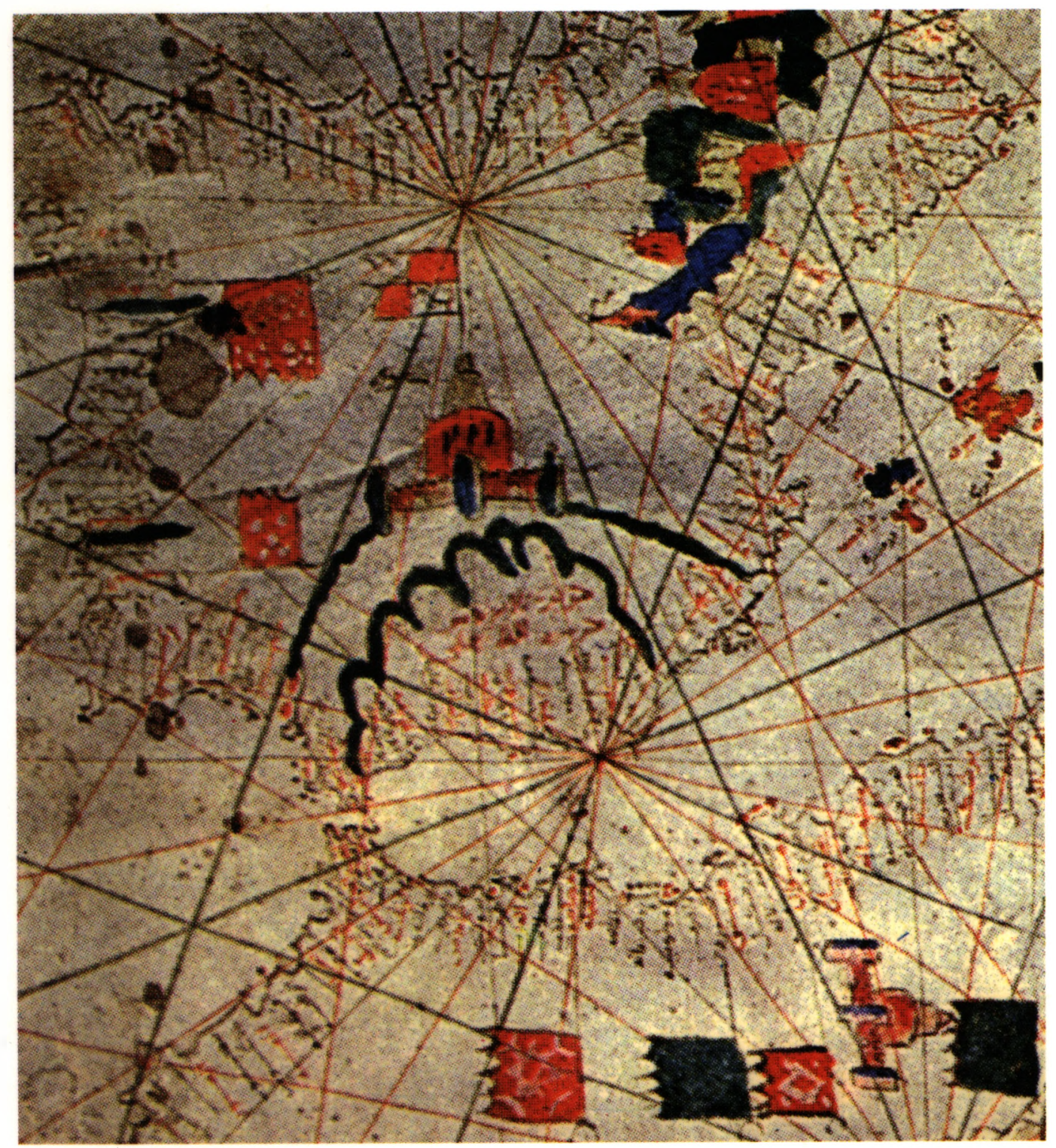

Núm. 12, Teruel-Alicante, 1995

Centro de Estudios Mudéjares - Instituto de Estudios Turolenses Área de Estudios Árabes e Islámicos de la Universidad de Alicante 
SHARQ AL-ANDALUS

Estudios Mudéjares y Moriscos

\author{
Director \\ María Jesús Rubiera Mata \\ Co-Director \\ Esteban Sarasa \\ Secretario de redacción \\ Luis F. Bernabé Pons \\ Co-Secretario \\ Antonio Gargallo Moya ( $†$ ) \\ Coordinador \\ Francisco Javier Sáenz Guallar \\ Comité de redacción \\ Gonzalo Borrás Gualis \\ Míkel de Epalza \\ Francisco Franco Sánchez \\ Bernard Vincent \\ Jesús Zanón Bayón
}

\title{
Comité Asesor
}

Comité Científico del Centro de Estudios Mudéjares, con exclusión de las personas mencionadas anteriormente

\section{Portada}

Fragmento peninsular del portulano árabe de Ibrahim de Murcia, Trípoli, 1463

$$
\begin{gathered}
\text { Depósito Legal } \\
\text { Z-2.924-96 } \\
\text { Impresión } \\
\text { INO Reproducciones, S. A. }
\end{gathered}
$$

Ctra. de Castellón, km 3,800, Pol. Miguel Servet, nave 13, 50013 Zaragoza

$$
\text { Editores }
$$

CENTRO DE ESTUDIOS MUDÉJARES - INSTITUTO DE ESTUDIOS TUROLENSES

\section{ÁREA DE ESTUDIOS ÁRABES E ISLÁMICOS DEL DEPARTAMENTO \\ DE FILOLOGÍAS INTEGRADAS - UNIVERSIDAD DE ALICANTE}

El Centro de Estudios Mudéjares es una institución adscrita al Instituto de Estudios Turolenses y patrocinada por el Gobierno de Aragón,

la Excma. Diputación Provincial de Teruel, el Excmo. Ayuntamiento de Teruel y la Caja de Ahorros de la Inmaculada

\section{Difusión}

CENTRO DE ESTUDIOS MUDÉJARES

(Instituto de Estudios Turolenses, Apdo. de Correos 77, 44080 Teruel) 